\title{
VISUAL ACUITY OUTCOME ANALYSIS AND SPECTACLE INDEPENDENCE AFTER TORIC MULTIFOCAL INTRAOCULAR LENS IMPLANTATION IN CATARACT PATIENTS
}

\author{
Ashok Balagopal1, Ramesh Rajasekaran², Meenakumari33, Prasanna Venkatesh Ramesh4, Kalai Mohan ${ }^{5}$ \\ ${ }_{1}^{1}$ General Ophthalmologist, Department of Ophthalmology, Mahathma Eye Hospital, Tiruchirappalli, Tamilnadu, India. \\ ${ }^{2}$ Chairman, Department of Ophthalmology, Mahathma Eye Hospital, Tiruchirappalli, Tamilnadu, India. \\ ${ }_{3}^{3}$ Medical Director, Department of Ophthalmology, Mahathma Eye Hospital, Tiruchirappalli, Tamilnadu, India. \\ ${ }^{4}$ Fellow-Medial Officer, Dr. Sathyan Hospital, Coimbatore, Tamilnadu, India. \\ ${ }_{5}^{5}$ General Ophthalmologist, Department of Ophthalmology, Mahathma Eye Hospital, Tiruchirappalli, Tamilnadu, India.
}

\section{ABSTRACT}

\section{BACKGROUND}

The present study is carried out to evaluate the visual outcome after performing cataract surgery with toric multi focal IOL implantation. Toric multifocal IOL implantation is an outcome to meet the need of patients for spectacle independence in cataract patients. This technology is applied in patients with cataract and also pre-existing corneal astigmatism of more than $1.25 \mathrm{D}$ who were dependent on spectacles for distance vision.

\section{MATERIALS AND METHODS}

This is a retrospective cohort study conducted in a single centre by a single surgeon. 40 eyes of 20 patients with cataract and preexisting corneal astigmatism of more than 1.25 D (D) were analysed in the study at Mahathma Eye Hospital, Trichy, Tamil Nadu, India. AMO ECToric multifocal IOL was used. Both sexes in the age group 30-80 were enrolled. Uncorrected distance visual acuity (UDVA), and best corrected visual acuity (BCVA) were assessed using Snellen visual acuity chart at 3 months post op. Rotational stability of the IOL was assessed by slitlamp method. Patient satisfaction was studied by the questionnaire called Response Rating Scale. All the patients received toric multifocal IOL implants. All patients were bilaterally treated.

\section{RESULTS}

All the patients studied had total spectacle independence. $90 \%$ of them had uncorrected visual acuity $6 / 6$ after careful preoperative patient selection, un-complicated phacoemulsification, selecting appropriate IOL formula and using a toric multi focal IOL with good rotational stability.

\section{CONCLUSION}

Toric multifocal IOL is a reliable and safe technology that could be confidently used in patients with cataract and co-existing precorneal astigmatism to achieve the goal of spectacle independence for distance, near and intermediate vision.

\section{KEY WORDS}

Toric Multifocal, Cataract, Astigmatism, Corneal, Visual Activity, Response Rating Scale.

HOW TO CITE THIS ARTICLE: Balagopal A, Rajasekaran R, Meenakumari, et al. Visual acuity outcome analysis and spectacle independence after toric multifocal intraocular lens implantation in cataract patients. J. Evolution Med. Dent. Sci. 2018;7(50): 5358-5362, DOI: $10.14260 /$ jemds/2018/1186

\section{BACKGROUND}

Pre-existing corneal astigmatism of more than $1 \mathrm{D}$ is present in almost $1 / 3^{\text {rd }}$ of cataract patients undergoing surgery, $22 \%$ having $>1.5 \mathrm{D}$ of astigmatism, $8 \%$ of them $>2.0 \mathrm{D}$ of corneal astigmatism.1,2\&3 In 1992, Schimizu et al introduced the first Toric intraocular lens. This was a 3-piece polymethyl methacrylate implant which was non-foldable and inserted through a $5.7 \mathrm{~mm}$ incision. ${ }^{4}$ In the past, cataract surgery meant only to remove the opaque lens and implant an IOL and attain emmetropia. But now the expectation of the patient is not only emmetropia but spectacle independence for distance, intermediate and near.

'Financial or Other Competing Interest': None.

Submission 12-11-2018, Peer Review 30-11-2018,

Acceptance 03-12-2018, Published 10-12-2018.

Corresponding Author:

Dr. Ramesh Rajasekaran,

Chairman,

Mahathma Eye Hospital,

No. 6 Seshapuram, Tiruchirappalli,

Tamilnadu, India.

E-mail: meh.drramesh@gmail.com

DOI: $10.14260 /$ jemds/2018/1186
There are various options available when a patient with pre-existing corneal astigmatism of $1.25 \mathrm{D}$ wants to have a multi focal IOL. They have options like limbal relaxing incisions or opposite clear corneal incisions or other modalities of keratotomies, excimer laser etc. All these procedures have outcomes like overcorrection, under correction, high expense involved, wound healing problems, sometimes the disadvantage of an additional surgery. 5,6\&7 Hence, an IOL which optimally meets the need of a cataract patient for spectacle independence have to be identified. When the patient has pre-existing corneal astigmatism of more than $1.25 \mathrm{D}$, the patient is going to be spectacle dependent in the post- operative period. The post-operative astigmatism which existed pre-operatively, when a multi focal IOL was implanted-distance and intermediate visual acuities in those eyes were compromised. So, the present study evolved to analyse visual acuity outcome analysis and spectacle independence after toric multi focal intraocular lens implantation in cataract patients.

\section{MATERIALS AND METHODS}

This is a retrospective cohort study conducted on 40 eyes of 20 patients. Both male and female sexes were included in the 
study. The age group was between 40 and 80 years. This is a cross sectional study. This was conducted in a single centre, Mahathma Eye Hospital, Tamilnadu India, a tertiary care centre and all the surgeries done by a single ophthalmic surgeon. Toric multifocal IOL of a single company - ez toric AMO was used for the all the patients.

\section{Patient Selection Criteria \\ Inclusion Criteria}

The patient included in the study had significant cataract, pre-existing corneal astigmatism of more than $1.25 \mathrm{D}$. The patients with regular astigmatism were involved.

\section{Exclusion Criteria}

Patients with astigmatism of less than 1.25 D cylinder, irregular astigmatism, central corneal opacity, patients with flesh pterygium and irregular astigmatism, Fuchs endothelial dystrophy which might require corneal transplantation at a later stage, any form of keratoconus, pellucid marginal degeneration, chemical injuries were excluded from this study. Any other form of corneal dystrophies or degenerations were also excluded. It is a well -known fact that, multi focal IOL minimally reduces the contrast sensitivity. Hence, any comorbid ocular pathologies especially retinal or macular pathologies, retinal surgeries, glaucomatous eyes, are all rejected from this study. Patients with history of amblyopia or strabismus surgeries were rejected as there will not be any summation effect. One -eyed patients were excluded.

\section{Pre-Op Procedures}

A careful history taking was done by prolonged chair time. This helped us to understand a patient with Type A personality and refuse toric multifocals in a patient with over expectation. Time was taken to explain the possibilities of photic phenomena (Glare, haloes) and whether the patient would accept it as a trade-off for spectacle independence. Patients with highly demanding near vision task were not included in this study. In this study, all the patients were bilaterally treated with toric multifocal IOL implants.

\section{Pre-Operative Assessment}

All patients had detailed evaluation in the form of visual acuity-unaided and aided, refraction using manual retinoscopy method, assessing the pupil status using pupillometry, grading of the cataract by LOS 3, was done. Fundus examination was performed by $90 \mathrm{D}$ lens and also by indirect ophthalmoscopy. An exhaustive attempt was made to precisely quantify the pre-existing astigmatism by using manual keratometry (Bausch \& Lomb model), auto refractokeratometry, understanding the previous prescriptions, comparing with the current retinoscopy etc. Corneal topography was done to look for bowtie. Posterior cornea was studied by Scheimpflug imaging. This helped us to eliminate the patients with posterior corneal astigmatism. Aberrometry was done for all the patients. Patients with higher order aberrations of coma more than 33 are rejected from the study. In our study, we relied more on the manual keratometry by a single user and well calibrated, as a gold standard. Immersion Biometry was done for all the patients and we also applied SRK-T formula. ${ }^{8}$ AMO EC.com toric calculator was used. Surgeon induced astigmatism (S I A) was calculated for 100 surgeries by using Hill.com software for the single surgeon operating on the patients.

\section{Intra-Ocular Lens}

All patients had an implantation made of acrylic material and hydrophobic surface. They were all single piece lens with aspheric design. Incident light like green light for near vision is $50 \%$ and distance is $50 \%$, blue light for near vision is $71 \%$ and distance is $29 \%$. Red light for near vision is $38 \%$ and distance is $62 \%$ distributed $65-\%$ for distance focus and 35 $\%$ for near focus. The IOL power was calculated using AMO EC.com toric calculator. The SIA was incorporated in the IOL power calculation software.

\section{Pre-Marking}

Pre-marking was done in sitting posture. Three reference markings are done at 3, 6, and 9'o clock position using a sterile marker pen after applying topical anaesthesia. Sitting posture was preferred to avoid cyclotorsion. Slitlamp was used and a thin beam of slit was placed on the cornea to mark at 3 and 9 O'clock position. Vertically placed slit beam was used to confirm $90^{\circ}$ axis. This was done after applying lid speculum. At the time of surgery to mark the axis of placement, Mendez's marker was used.

\section{Phacoemulsification and Toric Multi Focal IOL Implantation}

All surgeries were performed under topical anaesthesia by a single surgeon using closed chamber technique. $2.2 \mathrm{~mm}$ limbal corneal incision was made. $5.5 \mathrm{~mm}$ rhexis marker was imprinted on the cornea, so that a rhexis of $5 \mathrm{~mm}$ was made to achieve an overlap of $1 \mathrm{~mm}$ all around the centrally placed $6 \mathrm{~mm}$ optic. Efficient phacoemulsification was performed by using ideal phacodynamics and minimal ultrasound energy. Appropriate phaco-techniques were used to suit various grades of cataracts. Toric multifocal IOL was placed in the bag under viscoelastics. The marking on the IOL was aligned with the corneal marking. Visco elastics under the IOL was washed well for the rotational stability of the IOL. Visual acuity was assessed using Snellen visual acuity chart in the 1 month and 3 months post-op period. The axis marking on the IOL was confirmed by rotating the slit beam. This was done at 1 month and 3 months post op. All the results were documented for 3 months post op.

\section{RESULTS}

In the present study, an analysis of visual acuity outcome and spectacle independence after toric multifocal intraocular lens implantation in cataract patients was carried out.

\section{Analysis based on Age}

The patients were screened age wise for the treatment. The results showed that, out of 40 eyes of 20 patients, 15 belongs to $61-70$ yrs., 12 belongs to $51-60$ yrs., 10 belongs to $71-80$ yrs. and only 3 are 41-50 yrs. of age. Majority of the patients opting for spectacle independence fall within the age group of 50-80 which comprises of highly active and productive age group as well as retired senior citizen age group. In elderly age group, where there were hand tremors, dementia, and forgetfulness highly benefited out of spectacle independence. The results were shown in Figures- 1 \& 2 . 


\section{Quantifying the Pre-Existing Corneal Astigmatism}

The selected patients were subjected for evaluation of preexisting corneal astigmatism before cataract surgery. The results showed that, out of 40 eyes, 34 eyes had cylinder power of 1.0-2.00 D and 6 eyes had 2.25-3.00 D (Table - 1). None of the patients under-going toric multi focal IOL implantation had astigmatism of more than 3D. All these patients were counselled for toric multifocal IOL implantation to fulfil their needs for spectacle independence for all distances.

\section{Axial Length of 40 Eyes in Patients undergoing Toric Multifocal IOL Implantation}

The axial length of the 40 eyes of the selected patients were measured. Out of 40 eyes of patients, 28 had axial length of 22-24 mm, 9 had axial length of 24-26 mm while 3 had axial length of 20-22 mm after treatment with the toric multifocal IOL (Table - 3). Patients with small eyes with a axial length of $20-22 \mathrm{~mm}$, normal length 22-24 mm, large eyes with 24-26 $\mathrm{mm}$ were best suited for this toric multifocal IOL implantation. Very high myopes with a axial length more than $26 \mathrm{~mm}$, because of large bag are known to have rotational instability in patients opting for toric multi focal IOL implantation. Moreover, higher the myopia, longer the axial lengths, most of the patients had macular pathology hence unsuitable to undergo this technology.

\section{An Analysis of Targeted Residual Astigmatism}

The targeted residual astigmatism of cataract patients showed that, 33 eyes had targeted residual astigmatism of 0.01-0.10 D, 6 had 0.11-0.20 D and only 1 had 0.21-0.30 D (Table - 4). This precise refractive outcome is possible because of improved surgical techniques and technology. Precise pre-op astigmatism assessment choosing the right IOL formula, precision in surgical technique combined with technology has made the above said outcome possible.
Frequency Distribution of the Respondents based on their Uncorrected Visual Acuity after 3 Months PostOperative Period.

The result of uncorrected visual acuity of 40 eyes of 20 patients in three months post op was predicted in table -5 . Among them, 17 eyes had 6/9 visual acuity 16 eyes had 6/6, 7 eyes had $6 / 12$ and none had spectacle dependency. The patients with $6 / 12$ and $6 / 9$ vision all had minimal refractive error of +/- 0.5 D. None of the patients had a refractive error or residual astigmatism more than $0.5 \mathrm{D}$.

Frequency Distribution of the Respondents based on their Near Vision Acuity after 3 Months of Toric Multifocal IOL Implantation

The results of near vision acuity of the patients after toric multifocal IOL implantation for cataract surgery revealed, 35 eyes had N6 near visual acuity, 5 eyes had N8 (Table - 6). After surgery all the patients had good reading speed under good illumination. One was a tailor by occupation who was also comfortable. None of the patients required spectacles for their near vision.

Frequency Distribution of the Respondents of the Patients with Residual Post-0p Error (Spherical and Cylinder)

The number of eyes of patients based on the residual post operative spherical/cylinder error was carried out. The results showed that, among 40 eyes, 36 eyes had 0.00 error and only 4 eyes had residual refractive error of $+/$ - 0.5 spherical/cylindrical error. The resulted were interpreted in table - 7. All these patients had total spectacle independency for near, intermediate and infinity. The visual outcome analysis confirms that AMO Toric Multifocal IOL gives total spectacle independence in all the patients included in our study. Its rotational stability gave sustained visual acuity with consistency.

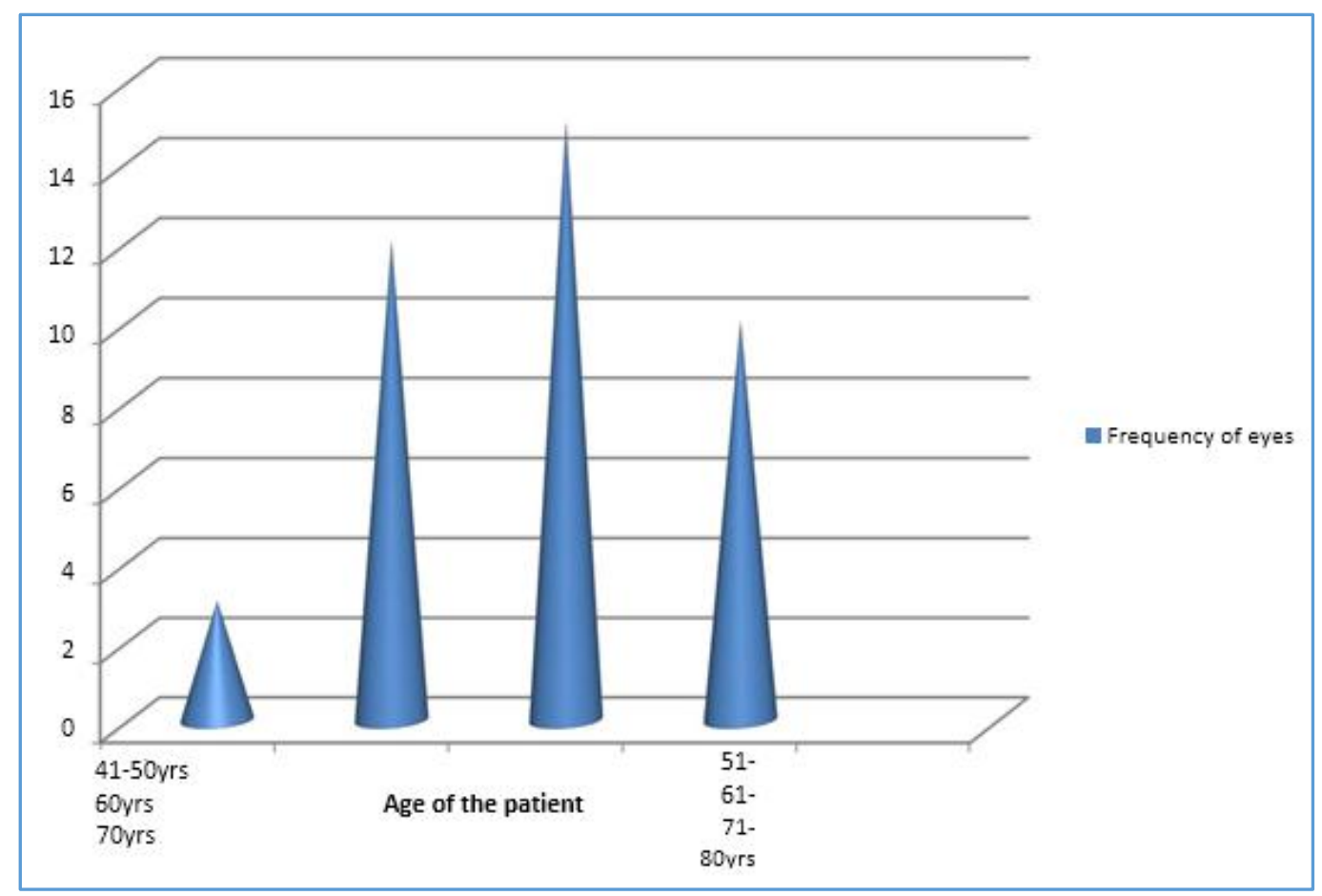

Figure 1. Age Wise Frequency Distribution of Respondents with Pre-Existing Corneal Astigmatism treated with Toric Multifocal IOL Implant 


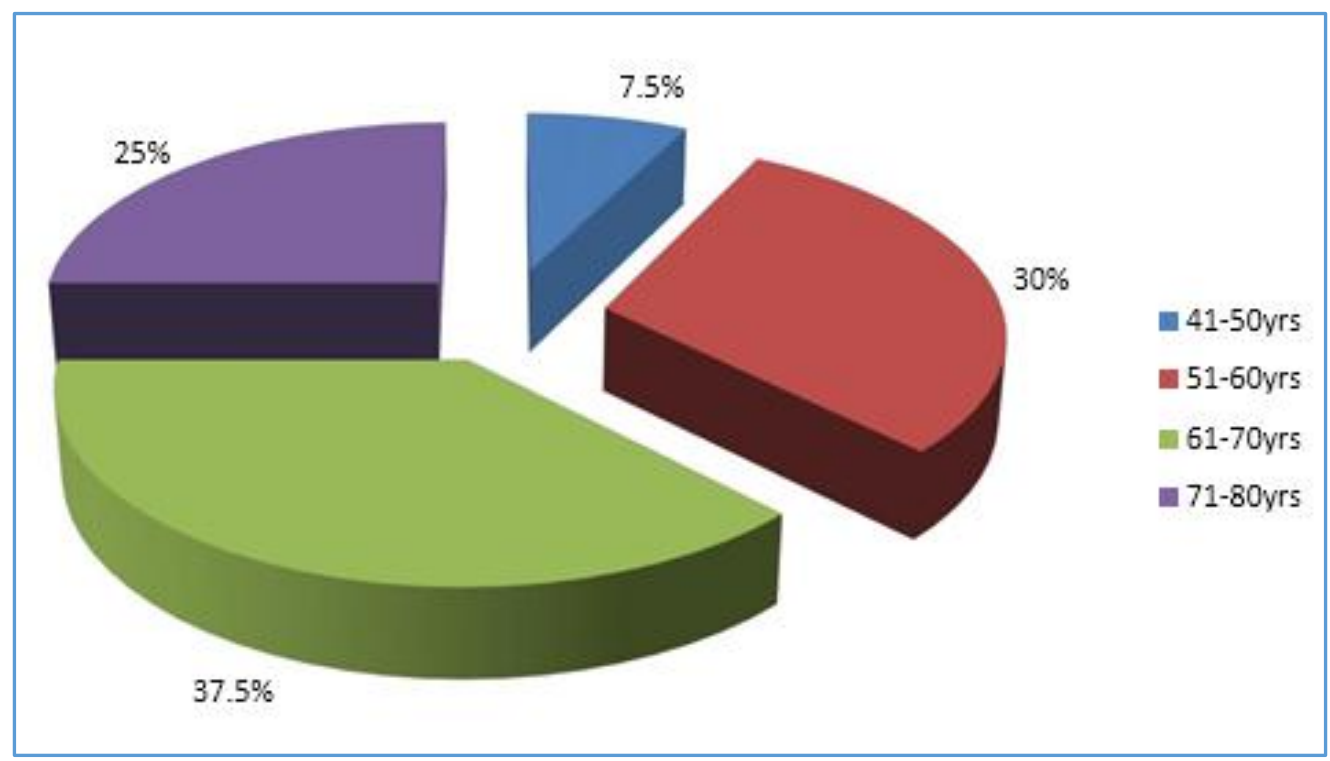

Figure 2. Percentage of Age Wise Frequency Distribution of Respondents with Pre-Existing Corneal Astigmatism Treated with Toric Multifocal IOL Implant

\begin{tabular}{|c|c|c|}
\hline Gender & Frequency of Eyes & Percentage (\% of Eyes) \\
\hline Male & 17 & 42.5 \\
\hline Female & 23 & 57.5 \\
\hline Total & 40 & 100.0 \\
\hline $\begin{array}{r}\text { Table 1. Gender Wise Frequency Distribution of Multifocal } \\
\text { IOL Respondents Treated with Toric Multifocal IOL }\end{array}$ \\
\hline
\end{tabular}

\begin{tabular}{|c|c|c|}
\hline $\begin{array}{c}\text { Pre-Existing Cylinder } \\
\text { Power of Eyes }\end{array}$ & $\begin{array}{c}\text { Frequency of } \\
\text { Eyes }\end{array}$ & $\begin{array}{c}\text { Percentage (\%) of } \\
\text { Eyes }\end{array}$ \\
\hline $1.01-2.00$ & 34 & 85.0 \\
\hline $2.01-3.00$ & 6 & 15.0 \\
\hline Total & $\mathbf{4 0}$ & $\mathbf{1 0 0 . 0}$ \\
\hline
\end{tabular}

Table 2. Frequency Distribution of the Respondents based on their Pre-Existing Corneal Regular Astigmatism

\begin{tabular}{|c|c|c|}
\hline $\begin{array}{c}\text { Axial length } \\
\text { of Eyes }\end{array}$ & $\begin{array}{c}\text { Frequency } \\
\text { of Eyes }\end{array}$ & $\begin{array}{c}\text { Percentage } \\
\text { (\%) of Eyes }\end{array}$ \\
\hline $20-22 \mathrm{~mm}$ & 3 & 7.5 \\
\hline $22-24 \mathrm{~mm}$ & 28 & 70.0 \\
\hline $24-26 \mathrm{~mm}$ & 9 & 22.5 \\
\hline Total & $\mathbf{4 0}$ & $\mathbf{1 0 0 . 0}$ \\
\hline
\end{tabular}

Table 3. Frequency Distribution of Respondents based on the Axial Length of the Eye Treated with Toric Multifocal IOL

\begin{tabular}{|c|c|c|}
\hline $\begin{array}{c}\text { Target Residual } \\
\text { Astigmatism }\end{array}$ & $\begin{array}{c}\text { Frequency } \\
\text { of Eyes }\end{array}$ & $\begin{array}{c}\text { Percentage } \\
\text { (\% of Eyes) }\end{array}$ \\
\hline $0.01-0.10$ & 33 & 82.5 \\
\hline $0.11-0.20$ & 6 & 15.0 \\
\hline $0.21-0.30$ & 1 & 2.5 \\
\hline Total & $\mathbf{4 0}$ & $\mathbf{1 0 0 . 0}$ \\
\hline $\begin{array}{r}\text { Table 4. Frequency Distribution of Respondents based on } \\
\text { the Target Residual Astigmatism }\end{array}$ \\
\hline
\end{tabular}

\begin{tabular}{|c|c|c|}
\hline This UCVA & Frequency of Eyes & Percentage of Eyes (\%) \\
\hline $6 / 6$ & 16 & 40 \\
\hline $6 / 9$ & 17 & 42.5 \\
\hline $6 / 12$ & 7 & 17.5 \\
\hline Total & $\mathbf{4 0}$ & $\mathbf{1 0 0 . 0}$ \\
\hline $\begin{array}{c}\text { Table 5. Frequency Distribution of the Respondents based } \\
\text { on their Uncorrected Visual Acuity after } 3 \text { Months of } \\
\text { Multifocal and Toric Model Treatment }\end{array}$ \\
\hline
\end{tabular}

\begin{tabular}{|c|c|c|}
\hline $\begin{array}{c}\text { Near Vision } \\
\text { Acuity }\end{array}$ & $\begin{array}{c}\text { Frequency of } \\
\text { Eyes }\end{array}$ & $\begin{array}{c}\text { Percentage } \\
\text { (\% of Eyes) }\end{array}$ \\
\hline N6 & 35 & 87.5 \\
\hline N8 & 5 & 2.5 \\
\hline $\begin{array}{c}\text { Table 6. Frequency Distribution of the Respondents based } \\
\text { on their Near Vision Acuity after 3 Months of Toric } \\
\text { Multifocal IOL Implantation }\end{array}$ \\
\hline \multicolumn{2}{|c|}{}
\end{tabular}

\begin{tabular}{|c|c|c|}
\hline $\begin{array}{c}\text { Post-Op Residual } \\
\text { Refractive Error (+/-) }\end{array}$ & $\begin{array}{c}\text { Frequency of } \\
\text { Eyes }\end{array}$ & $\begin{array}{c}\text { Percentage (\%) } \\
\text { of Eyes }\end{array}$ \\
\hline 0.00 & 36 & 90 \\
\hline 0.50 & 4 & 10 \\
\hline Total & $\mathbf{4 0}$ & 100.0 \\
\hline $\begin{array}{c}\text { Table 7. Frequency Distribution of the Respondents of the } \\
\text { Patients with Residual Post-Op Error } \\
\text { (Spherical and Cylinder) }\end{array}$ \\
\hline
\end{tabular}

\section{DISCUSSION}

With evolution and understanding of excellent phacoemulsification techniques complimented by equipment with technology to manage all grades of cataract under any circumstances has encouraged the surgeons to predict the outcome of their surgeries. The patient's expectation for spectacle independence is also increasing. With the preexisting corneal astigmatism in cataract patients, Toric IOL is the lens of choice offering spectacle independence for distance. To reward the patient's expectation of spectacle independence for near and intermediate multi focal IOL is the lens of choice. In cataractous eyes with astigmatism of more than $1 \mathrm{D}$, if multi focal IOL is used certainly there are comprises in the visual acuity. Hence astigmatism of more than 1D needs to be corrected. ${ }^{9}$ Though there are various methods like Lasik, LRI's, OCCI to correct pre-existing astigmatism, they are all another addon or individual surgical procedures. 10 \& 11 But, Toric multi focal IOLs offer the technology to correct pre-existing corneal astigmatism and give spectacle independence for distance intermediate and near as a single surgical procedure as analysed in the present study. 
The AMO Toric multifocal IOL offers 2 technologies namely toricity and multifocality. Various Toric multifocal IOLs are available namely diffractive AT Lisa Toric IOL, the refractive $M$ - flex $T$ IOL, the Lentist $M+$ Toric IOL, the diffractive Acrysof Toric restore toric IOL. In our study, using AMO toric multifocal IOL, there is $100 \%$ spectacle independence in all patients. Similar findings were reported by Visseret al. (2011) ${ }^{12}$ and Tiago et al. (2013) ${ }^{13}$ and they identified that, the AT Lisa Toric IOLs had good predictability and visual acuity for all distance, and patient satisfaction.

The spectacle independence in our study was $100 \%$ at 3 months follow up. This was similar to a prospective study conducted by Ferreira et al. (2013) ${ }^{14}$ and they concluded that implantation of the diffractive multifocal toric IOL in patients with cataract and corneal astigmatism provided excellent distance, intermediate, and near visual outcomes. This allowed all the patients total spectacle independence due to predictable refractive results.

\section{CONCLUSION}

Our study shows that the implantation of the AMO Technis Toric Multifocal IOL in cataractous patients with pre-existing corneal astigmatism provided excellent distance, near, intermediate visual outcomes. The assured rotational stability of this aspheric hydrophobic toric multifocal IOL is encouraging. Hence there is effective reduction in the refractive error and excellent restoration of visual function. This predictable visual acuity outcome meets today's patients' demands of total spectacle independence.

\section{REFERENCES}

[1] Holland E, Lane S, Horn JD, et al. The Acrsof toric intraocular lens in subjects with cataracts and corneal astigmatism: a randomized, subject - masked, parallelgroup, 1-year study. Ophthalmology 2010;117(11):2104-11.

[2] Hoffmann, Hutz WW. Analysis of biometry and prevalence data for corneal astigmatism in 23, 239 eyes. J Cataract Refract Surg 2010;36(9):1479-85.

[3] Ferrer-Blasco T, Montes-Mico R, Peixoto-de-Matos SC, et al. Prevalence of corneal astigmatism before cataract surgery. J Cataract Refract Surg 2009;35(1):70-5.

[4] Hayashi K, Manabe S, Yoshida M, et al. Effect of astigmatism on visual acuity in eyes with a diffractive multifocal intraocular lens. J Cataract Refract Surg 2010;36(8):1323-9.
[5] Shimizu K, Misawa A, Suzuki Y. Toric intraocular lenses: corrected astigmatism while controlling axis shift. J Cataract Refract Surg 1994;20(5):523-6.

[6] Schallhorn SC, Venter JA. One-month outcomes of wave front-guided LASIK for low to moderate myopia with the VISX STAR S4 laser in 32, 569 eyes. J Refract Surg 2009;25(Suppl 7):S634-S41.

[7] Thomas KE, Brunstetter T, Rogers S, et al. Astigmatism: risk factor for post-operative corneal haze in conventional myopic photorefractive keratectomy. J Cataract Refract Surg 2008;34(12):2068-72.

[8] Bayramlar H, Daglioglu Mc, Borazan M. Limbal relaxing incisions for primary mixed astigmatism and mixed astigmatism after cataract surgery. J Cataract Refract Surg 2003;29(4):723-8.

[9] Retzlaff JA, Sanders DR, Kraff MC. Development of the SRK/T intraocular lens implant power calculation formula. J Cataract Refract Surg 1990;16(3):333-40.

[10] Fernandez-Vega L, Alphonso JF, Montes-Mico R, et al. Visual acuity tolerance to residual refractive errors in patients with an apodized diffractive intraocular lens. J Cataract Refract Surg 2008;34(2):199-204.

[11] Muftuoglu O, Prasher P, Chu C, et al. Laser in situ keratomileusis for residual refractive errors after apodized diffractive multifocal intraocular lens implantation. J Cataract Refract Surg 2009;35(6):1063-71.

[12] Muftuoglu 0, Dao L, Cavanagh HD, et al. Limbal relaxing incisions at the time of apodized diffractive multi focal intraocular lens implantation to reduce astigmatism with or without subsequent laser in situ keratomileusis. J Cataract Refract Surg 2010;36(3):456-64.

[13] Visser N, Nuijts RM, de VRies NE, et al. Visual outcomes and patient satisfaction after cataract surgery with toric multifocal intraocular lens implantation. J Cataract Refract Surg 2011;37(11):2034-42.

[14] Ferreira TB, Marques EF, Rodrigues A, et al. Visual and optical outcomes of a diffractive multifocal toric intraocular lens. J Cataract Refract Surg 2013;39(7):1029-35. 